\title{
Evaluation of Antioxidant Potentials and $\alpha$-Amylase Inhibition of Different Fractions of Labiatae Plants Extracts: As a Model of Antidiabetic Compounds Properties
}

\author{
Soheila Moein,, ${ }^{1,2}$ Elham Pimoradloo, ${ }^{3}$ Mahmoodreza Moein, ${ }^{4,5}$ and Mahmood Vessal ${ }^{6}$ \\ ${ }^{1}$ Molecular Medicine Research Center, Hormozgan Health Institute, Hormozgan University of Medical Sciences, Bandar Abbas, Iran \\ ${ }^{2}$ Department of Biochemistry, Faculty of Medicine, Hormozgan University of Medical Sciences, Bandar Abbas, Iran \\ ${ }^{3}$ Department of Biochemistry, Fars Sciences and Research Branch, Islamic Azad University, Shiraz, Iran \\ ${ }^{4}$ Medicinal Plants Processing Research Center, Shiraz University of Medical Sciences, Shiraz, Iran \\ ${ }^{5}$ Department of Pharmacognosy, School of Pharmacy, Shiraz University of Medical Sciences, Shiraz, Iran \\ ${ }^{6}$ Department of Biochemistry, Faculty of Basic Sciences, Islamic Azad University of Shiraz, Sadra City, Fars, Iran
}

Correspondence should be addressed to Mahmoodreza Moein; mrezamoein@yahoo.com

Received 19 May 2017; Accepted 27 July 2017; Published 10 September 2017

Academic Editor: Kazim Husain

Copyright (C) 2017 Soheila Moein et al. This is an open access article distributed under the Creative Commons Attribution License, which permits unrestricted use, distribution, and reproduction in any medium, provided the original work is properly cited.

In an attempt to identify herbal drugs which may become useful in the prevention of diabetes, antioxidant potentials and $\alpha$-amylase inhibition by the ethanol extracts of two plants belonging to Lamiaceae family, Otostegia persica and Zataria multiflora, and their different fractions were studied. Also, inhibition of $\alpha$-amylase by Salvia mirzayanii and its fractions was evaluated. All of the samples exhibited antioxidant activities, among which ethyl acetate fraction of Zataria multiflora (17.21 $\pm 0.17 \mathrm{mg}$ GAE/g) was found to contain the highest amounts of phenols and the ethyl acetate fraction of Zataria multiflora (218 $\pm 2.76 \mathrm{mg}$ QUE/g) had the most values of flavonoids. Ethyl acetate fraction of Zataria multiflora $\left(\mathrm{IC}_{50}=3.05 \pm 0.51 \mu \mathrm{g} / \mathrm{ml}\right.$ ) was shown to have the most reducing power and the ethyl acetate fraction of Zataria multiflora $\left(\mathrm{IC}_{50}=32.17 \pm 1.82 \mu \mathrm{g} / \mathrm{ml}\right)$ exhibited the highest DPPH radical scavenging. The ethyl acetate fraction of Otostegia persica $(99.39 \pm 0.94 \%)$ showed the highest $\alpha$-amylase inhibitory activity which was similar to acarbose used as a standard. Mode of $\alpha$-amylase inhibition of the most samples was uncompetitive except for ZMC, OPP, OPC, and SMP which presented competitive inhibition. The present findings showed that studied samples may have some compounds with antioxidant and antidiabetic effects.

\section{Introduction}

Type 2 diabetes (T2D) affects a large population worldwide. T2D is a complex heterogeneous group of metabolic disorders including hyperglycemia and impaired insulin action and/or insulin secretion and causes dysfunctioning of multiple organs or tissues. Current theories of T2D include a defect in insulin-mediated glucose uptake in muscle, a dysfunction of the pancreatic $\beta$-cells, a disruption of the secretory function of adipocytes, and an impaired insulin action in the liver [1]. The early stage of type 2 diabetes is associated with postprandial hyperglycemia due to impaired pancreas after meal.

Hyperglycemia is believed to increase the production of free radicals and reactive oxygen species, leading to oxidative tissue damage and diabetic complications such as nephropathy, neuropathy, retinopathy, and memory impairment [2].

Glucosidases are a group of digestive enzymes which break down the dietary carbohydrates into simple monosaccharides. Glucosidase inhibitors such as acarbose reduce the rate of carbohydrate digestion and delay the carbohydrate absorption from the digestive tract; therefore, they have a potential to prevent the development of type 2 diabetes by lowering the after meal glucose levels [3]. Natural compounds from ancient times have been regarded as the most important sources of supplying drugs and now half of the drugs are from natural origin. In recent years, because of the availability of these compounds, having renewable resources, low toxicity, and low cost for preparing them [4], there is a tendency 
to isolate active compounds from natural sources. Labiatae family (Lamiaceae) is one of the largest and most distinctive families of flowering plants, with about 220 genera and almost 4000 species worldwide. This family has an almost cosmopolitan distribution; moreover, Labiatae family is best known for the essential oils common to many members of the family. Many biological active essential oils have been isolated from various members of this family; in addition to, Labiatae family is also famous for the presence of diterpenoids [5] and polyphenolic compounds [6]. "Antioxidant compounds such as polyphenols are common in plants; however, the most concentrations of these components are present specially in fruits such as apples, grapes, blackberries, and strawberries [7]. These components can scavenge free radicals and exert protective effects against cardiovascular diseases [7].”

In previous studies, polyphenolic compounds were reported to be strong $\alpha$-amylase inhibitors [8]. To achieve this, antidiabetic (inhibition of $\alpha$-amylase) and antioxidant properties of two plants extracts and their fractions were investigated. These two plants include Otostegia persica (Op) and Zataria multiflora $(\mathrm{Zm})$ which belong to Labiatae family. Also, inhibition of $\alpha$-amylase by Salvia mirzayanii (Sm) extract and its different fractions will be investigated. This plant belongs to Labiatae family.

\section{Materials and Methods}

2.1. Chemicals. DPPH (2,2-diphenyl-1-picrylhydrazyl radical), quercetin, gallic acid, $\alpha$-amylase and Folin-Ciocalteu reagent were obtained from Sigma Chemical Co. (St Louis, MO). All other reagents were obtained from Merck Chemicals (Darmstadt, Germany).

2.2. Plant Materials. The leaves of $O p$ and $S m$ were collected from Genu Mountains in the northeast of Bandar Abbas on 20 and 15 June 2012, while Zataria multiflora was obtained from a herbalist in Shiraz, June 2012; after that, the plants were identified by Dr. M. Moein. The voucher deposited in Medicinal Plants Processing Research Center, School of Pharmacy, Shiraz University of Medical Sciences. The voucher numbers of $O p, Z m$, and $S m$ are MPRCM 94-85, MPRCM 9483, and MPRCM 94-84, respectively.

2.3. Extraction and Fractionation. The leaves were separated, dried at room temperature, and were ground into a powder form; then, using a mixture of $70 \%$ ethanol in water, hydroalcoholic extracts of the powdered leaves were prepared by a percolation method and the extracts were subjected to fractionation by different solvents in order of increasing polarity (petroleum ether, chloroform, ethyl acetate, and butanol), respectively. The extracts and their fractions were concentrated by a rotary vacuum evaporator and kept at $+4^{\circ} \mathrm{C}$ until tested.

2.4. Determination of Total Phenols. Total phenol compound contents were determined by Folin-Ciocalteu method [9]. To start the reaction, $150 \mu \mathrm{l}$ of samples $(10 \mathrm{mg} / \mathrm{ml})$ was mixed with $750 \mu \mathrm{l}$ of Folin-Ciocalteu reagent $0.2 \mathrm{~N}$ and, after $3 \mathrm{~min}$, $600 \mu \mathrm{l}$ of $\mathrm{Na}_{2} \mathrm{CO}_{3}$ (7.5\%) was added. The mixture was put at room temperature in the dark for $30 \mathrm{~min}$. The phenolic contents were determined by colorimetric method at $765 \mathrm{~nm}$. Gallic acid was used as a standard and the total phenolic content in gallic acid equivalent (GAE) was calculated by the following formula:

$$
C=\frac{c v}{m}
$$

where $C$ is the total content of phenolic compounds $(\mathrm{mg} / \mathrm{g}$ plant extract or its fraction) in GAE; $c$ is the concentration of gallic acid established from the calibration curve $(\mathrm{mg} / \mathrm{ml})$; $v$ is the volume of extract $(\mathrm{ml})$; and $m$ is the weight of plant extract or its fractions.

2.5. Determination of Flavonoids Content. The flavonoid contents of $\mathrm{Zm}$ and $\mathrm{Op}$ extracts and their fractions were determined, based on a colorimetric assay [10] in which $0.5 \mathrm{ml}$ of different concentrations of quercetin $(12.5-300 \mu \mathrm{g} / \mathrm{ml})$ was used as a standard. Quercetin solutions were mixed with $2 \mathrm{ml}$ of deionized water, and, after $3 \mathrm{~min}, 150 \mu \mathrm{l}$ of $\mathrm{NaNO}_{2}(5 \%$ $\mathrm{w} / \mathrm{v})$ and $150 \mu \mathrm{AlCl}_{3}(10 \% \mathrm{w} / \mathrm{v})$ solutions were added, and, after $6 \mathrm{~min}, 2 \mathrm{ml}$ of $\mathrm{NaOH}(4 \% \mathrm{w} / \mathrm{v})$ was also added to the mixture and the volume of the assay mixture was raised to $5 \mathrm{ml}$ with distilled water. After vortexing, the mixture was incubated at room temperature for $15 \mathrm{~min}$ and its absorbance was measured at $510 \mathrm{~nm}$. Flavonoid content was determined as $\mathrm{mg}$ of quercetin equivalent, using an equation obtained from the standard quercetin calibration curve.

2.6. Determination of Reducing Power. The reducing power of the samples was determined according to the method of Duan et al. [11]. Briefly, $0.5 \mathrm{ml}$ of different concentrations of the samples (2.5 to $40 \mu \mathrm{g} / \mathrm{ml}$ in ethanol) was mixed with $1.25 \mathrm{ml}$ of $0.1 \mathrm{M}$ phosphate buffer ( $\mathrm{pH} 6.6)$ and $1.25 \mathrm{ml}$ of a $1 \%$ $(\mathrm{w} / \mathrm{v})$ solution of potassium ferricyanide; then, the mixture was incubated in a water bath at $50^{\circ} \mathrm{C}$ for $20 \mathrm{~min}$. Afterwards, $1.25 \mathrm{ml}$ of $10 \%(\mathrm{w} / \mathrm{v})$ trichloroacetic acid solution and $1.25 \mathrm{ml}$ of distilled water and $0.25 \mathrm{ml}$ of $0.1 \%(\mathrm{w} / \mathrm{v})$ solution of ferric chloride were added to $2.5 \mathrm{ml}$ of the mixture. Immediately the absorbance of the samples was measured at $700 \mathrm{~nm}$. Increase in the absorbance of the reaction mixture indicated increase in the reducing power. Gallic acid was used as a standard. The experiments were repeated three times and their averages were reported. The least concentration of the sample that exhibited $\mathrm{OD}=0.5$ was reported.

2.7. Determination of DPPH Radical Scavenging. The DPPH scavenging assay was performed according to procedures described by Moein et al. [12].

One-tenth $\mathrm{ml}$ of the samples with different concentrations $(12.5-800 \mu \mathrm{g} / \mathrm{ml})$ was mixed with $0.1 \mathrm{ml}$ of DPPH solution ( $0.5 \mathrm{mM}$ in methanol), incubated at $25^{\circ} \mathrm{C}$ in the dark for $30 \mathrm{~min}$, and the absorbance was measured at $490 \mathrm{~nm}$ using a microplate reader (Biotek, ELX 800). Quercetin was used as an antioxidant standard. The obtained data was used to determine the concentration of the sample required to scavenge $50 \%$ of the DPPH free radicals $\left(\mathrm{IC}_{50}\right)$. The percent inhibition was plotted against the concentrations of the extract and $\mathrm{IC}_{50}$ was obtained from the fitted linear curve. A lower 
$\mathrm{IC}_{50}$ demonstrates a more potent antioxidant potential. The results were expressed as the mean \pm SD of three replicates.

2.8. Determination of $\alpha$-Amylase Inhibition. $\alpha$-Amylase inhibitory activities of $\mathrm{Op}, \mathrm{Sm}$, and $\mathrm{Zm}$ extracts and their fractions were performed according to Ademiluyi et al. [13] with some modifications. Briefly starch solution $(2 \mathrm{mg} / \mathrm{ml})$ was obtained by boiling and stirring $20 \mathrm{mg}$ of starch in $10 \mathrm{ml}$ of $10 \mathrm{mM}$ sodium phosphate buffer ( $\mathrm{pH} \mathrm{6.9)}$ for $15 \mathrm{~min}$. The enzyme solution ( $4 \mathrm{unit} / \mathrm{ml}$ ) was prepared by mixing $0.001 \mathrm{~g}$ of $\alpha$-amylase (EC 3.2.1.1) in $1.5 \mathrm{ml}$ of the mentioned buffer. The extracts $(3.7 \mathrm{mg}$ ) were dissolved in $0.5 \mathrm{ml}$ ethanol to give concentration about $7.4 \mathrm{mg} / \mathrm{ml}$. Dinitrosalicylic acid (DNSA) was used as a color reagent. Stop solution contained $96 \mathrm{mM}$ 3,5-dinitrosalicylic acid $(10 \mathrm{ml})$ and $5.31 \mathrm{M}$ sodium potassium tartrate in $2 \mathrm{M}$ sodium hydroxide $(10 \mathrm{ml})$. To the plant extract $(10 \mu \mathrm{l}), 550 \mu \mathrm{l}$ of starch solution and $40 \mu \mathrm{l}$ of the enzyme solution were added in a tube, mixed and incubated at $37^{\circ} \mathrm{C}$ for $15 \mathrm{~min}$; then, $600 \mu \mathrm{l}$ of DNSA was added to this mixture and the tube was incubated at $85^{\circ} \mathrm{C}$ in a water bath. After $15 \mathrm{~min}$, the reaction mixture was removed from water bath and cooled. The absorbance was measured at $540 \mathrm{~nm}$ in a spectrophotometer (Kyoto, Japan). Individual blanks were prepared for correcting the background absorbance. Controls were conducted in an identical fashion, by replacing plant extracts with $1 \mathrm{ml}$ of ethanol. Acarbose was used as the positive control. $\alpha$-Amylase inhibitory activity was calculated as follows:

$$
\text { Inhibition }(\%)=100-\left(\frac{\mathrm{OD}_{\text {samp-blank }}}{\mathrm{OD}_{\text {cont-blank }}} \times 100\right) \text {, }
$$

where OD samp and OD cont were defined as the absorbance of the sample and the control, respectively.

\subsection{Determination of Kinetic Parameters of $\alpha$-Amylase Inhi-} bition. Inhibition patterns of the samples against $\alpha$-amylase were determined according to the method described by Kim et al. [14]. Briefly, a fixed amount of $\alpha$-amylase was incubated with increasing concentrations of starch as a substrate $(1-6 \mathrm{mg} / \mathrm{ml})$ at $37^{\circ} \mathrm{C}$ for $15 \mathrm{~min}$, in the absence or presence of the samples $(7.4 \mathrm{mg} / \mathrm{ml})$.

Reactions were terminated and the absorption measurements carried out as mentioned before. Amounts of the product liberated (maltose) were determined from corresponding standard curves and converted to reaction rates. Inhibition patterns were then determined by Lineweaver-Burk plot $(1 / v$ versus $1 /(S)$ ).

2.10. Statistical Analysis. All experiments were performed in triplicate and the data were expressed as mean \pm SD (standard deviation). Linear regression was performed for calculation $50 \%$ inhibitory concentration $\left(\mathrm{IC}_{50}\right)$. Microsoft EXCEL 2010 program and graph pad instate 3.0 software were used for data analysis. One-way analysis of variance (ANOVA) was used to assess the presence of significant differences $(p<0.01)$.

\section{Results}

3.1. Quantification of Phenolic Compounds. Total phenols and flavonoids contents of the plant extracts are presented in

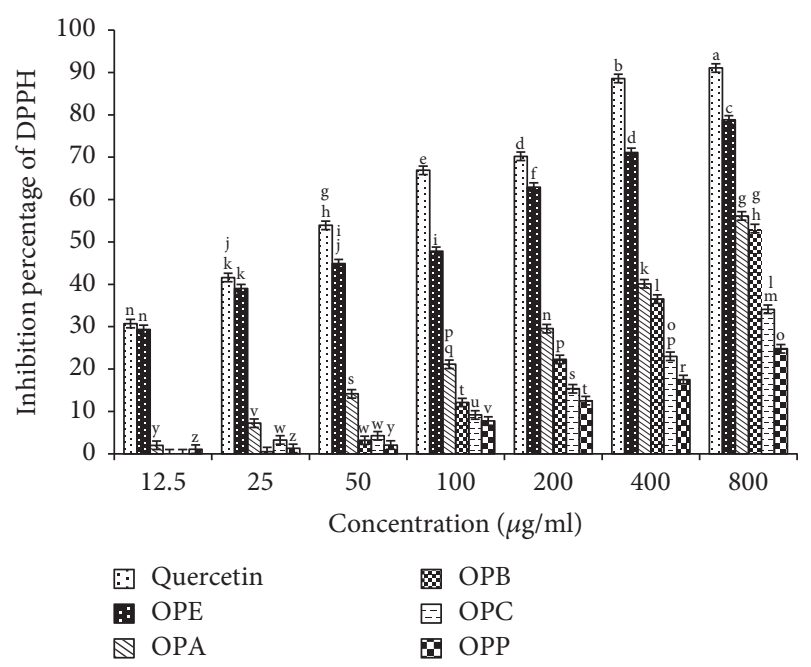

FIGURE 1: DPPH radical scavenging of Otostegia persica extract and its fractions in comparison with quercetin as an antioxidant standard.

Table 1. The results of phenol assay showed that, among $Z m$ extract and its fractions, $Z M A$ and $Z M P$ had the most and the least amounts of phenolic compounds, respectively. Among $O p$ extract and its fractions, $O P A$ and $O P P$ had the most and the least amounts of phenolic compounds. In general, the results of statistical analysis showed that there are significant differences between phenolic compounds in all of the samples $(p \leq 0.05)$.

The results about the flavonoids showed that, among $\mathrm{Zm}$ extract and its fractions, the highest amounts of flavonoids and the least amounts of flavonoids were in $Z M A$ and $Z M P$, respectively. Among $O p$ extract and its fractions, the highest and the least amounts of flavonoids were found in $O P P$ and $O P C$, respectively, as shown in Table 1.

3.2. Determination of Antioxidant Activities. Table 2 reveals the reducing power and radical $(\mathrm{DPPH})$ scavenging power of $\mathrm{Zm}$ and $\mathrm{OP}$ extracts and their fractions. The results of $\mathrm{DPPH}$ radical scavenging were reported as $\mathrm{IC}_{50}$, which show the concentrations of the samples which scavenge DPPH radical $50 \%$, and, in reducing power, the concentrations of the samples having an $\mathrm{OD}=0.5$ at $700 \mathrm{~nm}$ were reported.

Figures 1 and 2 show the DPPH radical scavenging of various concentrations of $\mathrm{Zm}$ and $\mathrm{Op}$ extracts and their fractions in comparison with quercetin as a standard.

Figures 3 and 4 present reducing power of various concentrations of $\mathrm{Zm}$ and $\mathrm{Op}$ extracts and their fractions in comparison with gallic acid as a standard.

3.3. Determination of $\alpha$-Amylase Inhibition. Alcoholic extracts of $Z m$ and $O p$ (ZME and OPE, resp.) and their different fractions were tested for $\alpha$-amylase inhibition using a colorimetric method as mentioned in methods. $\alpha$-Amylase inhibitory potentials of the extracts and their fractions were compared with acarbose as a standard under our specific set of assay conditions. As shown in Table 3, all of the samples except $Z M P$ had inhibitory effects on $\alpha$-amylase. 
TABLE 1: Total phenolic compounds and flavonoid contents of the plant extracts and their fractions $(p \leq 0.05)$.

\begin{tabular}{|c|c|c|}
\hline Samples & $\begin{array}{l}\text { Total phenol content } \\
\text { (mg GAE/g sample) }\end{array}$ & $\begin{array}{l}\text { Total flavonoids content } \\
\text { (mg QUE/g sample) }\end{array}$ \\
\hline Ethanol extractof $Z m$ & $3.01 \pm 0.07^{\mathrm{d}}$ & $64.73 \pm 1.66^{\mathrm{d}}$ \\
\hline Petroleum ether fraction of $Z m$ & $2.14 \pm 0.03^{\mathrm{e}}$ & $49.14 \pm 0.91^{\mathrm{e}}$ \\
\hline Chloroform fraction of $Z m$ & $8.01 \pm 0.06^{\mathrm{c}}$ & $81.06 \pm 1.89^{\mathrm{c}}$ \\
\hline Ethyl acetate fraction of $Z m$ & $17.21 \pm 0.17^{\mathrm{a}}$ & $218.19 \pm 2.76^{\mathrm{a}}$ \\
\hline Butanol fraction of $Z m$ & $12.28 \pm 0.12^{\mathrm{b}}$ & $112.88 \pm 2.76^{\mathrm{b}}$ \\
\hline Ethanol extract of $O p$ & $5.21 \pm 0.118^{\mathrm{b}}$ & $57.07 \pm 1.03^{\mathrm{b}}$ \\
\hline Petroleum ether fraction of $O p$ & $0.68 \pm 0.02^{\mathrm{e}}$ & $73.51 \pm 0.5^{\mathrm{a}}$ \\
\hline Chloroform fraction of $O p$ & $0.90 \pm 0.032^{\mathrm{d}}$ & $24.25 \pm 1.24^{\mathrm{e}}$ \\
\hline Ethyl acetate fraction of $O p$ & $7.07 \pm 0.11^{\mathrm{a}}$ & $40.37 \pm 1.06^{\mathrm{c}}$ \\
\hline Butanol fraction of $O p$ & $2.81 \pm 0.033^{\mathrm{c}}$ & $38.29 \pm 1.07^{\mathrm{d}}$ \\
\hline
\end{tabular}

Zm: Zataria multiflora, Op: Otostegia persica; statistical differences shown as alphabetic letters. The same alphabetic letters implied there are no statistical differences, $p>0.05$, and different letters represented statistical differences, $p<0.05$.

TABle 2: Antioxidant activities of Zataria multiflora and Otostegia persica extracts and their fractions.

\begin{tabular}{lcc}
\hline Samples & $\begin{array}{c}\text { DPPH radical scavenging } \\
\left(\mathrm{IC}_{50} \mu \mathrm{g} / \mathrm{ml}\right)\end{array}$ & $\begin{array}{c}\text { Reducing power } \\
\text { (concentrations with absorbance 0.5) }\end{array}$ \\
\hline Ethanol extractof $Z m$ & $90.73 \pm 2.92^{\mathrm{c}}$ & $4.15 \pm 0.013^{\mathrm{c}}$ \\
Petroleum ether fraction of $Z m$ & $883.26 \pm 2.18^{\mathrm{f}}$ & $5.83 \pm 0.20^{\mathrm{d}}$ \\
Chloroform fraction of $Z m$ & $440.75 \pm 3.09^{\mathrm{e}}$ & $11.36 \pm 0.07^{\mathrm{f}}$ \\
Ethyl acetate fraction of $Z m$ & $32.17 \pm 1.82^{\mathrm{b}}$ & $3.05 \pm 0.51^{\mathrm{b}}$ \\
Butanol fraction of $Z m$ & $393.78 \pm 1.55^{\mathrm{d}}$ & $7.57 \pm 0.24^{\mathrm{e}}$ \\
\hline Ethanol extract of $O p$ & $166.09 \pm 2.11^{\mathrm{b}}$ & $64.33 \pm 1.15^{\mathrm{c}}$ \\
Petroleum ether fraction of $O p$ & $1578.89 \pm 4.23^{\mathrm{f}}$ & $248.57 \pm 2.85^{\mathrm{f}}$ \\
Chloroform fraction of $O p$ & $1139.5 \pm 3.11^{\mathrm{e}}$ & $130.74 \pm 2.31^{\mathrm{e}}$ \\
Ethyl acetate fraction of $O p$ & $635.65 \pm 3.67^{\mathrm{c}}$ & $38.66 \pm 2.08^{\mathrm{b}}$ \\
Butanol fraction of $O p$ & $691.32 \pm 4.71^{\mathrm{d}}$ & $103.66 \pm 1.52^{\mathrm{d}}$ \\
Quercetin & $26.28 \pm 2.68^{\mathrm{a}}$ & $\mathrm{ND}^{\mathrm{N}}$ \\
Gallic acid & $\mathrm{ND}$ & $2.75 \pm 0.261^{\mathrm{a}}$ \\
\hline
\end{tabular}

ND: nondetermined, Zm: Zataria multiflora, Op: Otostegia persica; statistical differences shown as alphabetic letters. The same alphabetic letters implied there are no statistical differences, $p>0.05$, and different letters represented statistical differences, $p<0.05$.

3.4. Type 2 Diabetes of $\alpha$-Amylase Inhibition by the Samples. Table 3 demonstrates the $K_{m}$ and $V_{\max }$ values of the samples against $\alpha$-amylase. As compared to the uninhibited reaction, a decrease in $V_{\max }$ value was noted for the reactions with $Z M E, Z M B, Z M C, O P E, O P A$, and $O P B$ and no change in $V_{\max }$ value was noted in the reactions for $Z M C, O P C$, and $O P P$. The effects of the samples on $K_{m}$ were different too. This means that $K_{m}$ was constant in the reaction with $Z M C$, $O P C$, and $O P P$ and decreases in other samples. The types of inhibition of porcine pancreatic $\alpha$-amylase by different extracts and fractions and also by acarbose as a positive standard were obtained from Lineweaver-Burk plot (Figures 5,6 , and 7). The results suggested that the type of inhibition by acarbose and all of the fractions except $Z M C, O P C$, and $O P P$ was uncompetitive. In $Z M C, O P C$, and $O P P$ inhibition of $\alpha$-amylase may be competitive.

\section{Discussion}

"In an effort for identifying herbal drugs which may become useful in the prevention or alleviation of diabetes [15]," this study is performed. Herbal plants have long been used to treat diabetes, as their principal bioactive components showed good antidiabetic and antioxidant properties [16]. Many herbal plant extracts have been reported for their $\alpha$-amylase inhibitory activities but to date no such report was found for $\mathrm{Op}, \mathrm{Sm}$, and $\mathrm{Zm}$ extracts. These $\alpha$-amylase inhibitors are also called starch blockers since they prevent or slow down the absorption of starch into the body mainly by blocking the hydrolysis of 1,4-glycosidic linkages of starch and other oligosaccharides into maltose, maltotriose, and other simple sugars [17]. Based on our research, our study is the first report to state $\alpha$-amylase inhibition by leaves extracts of $O p$, 
TABLE 3: Percentage inhibition and kinetic parameters of $\alpha$-amylase in plant extracts and their fractions.

\begin{tabular}{|c|c|c|c|}
\hline Samples & $K m \mathrm{mM}$ & $V \max / \min$ & $\alpha$-Amylase inhibition $\%$ \\
\hline$\alpha$-Amylase without inhibitor & $4.2 \pm 0.004$ & $0.12 \pm 0.02$ & \\
\hline Acarbose & $0.95 \pm 0.02$ & $0.04 \pm 0.001$ & 100 \\
\hline Ethanol extract of $Z m$ & $0.66 \pm 0.01$ & $0.05 \pm 0.01$ & $47.23 \pm 1.2$ \\
\hline Petroleum ether fraction of $\mathrm{Zm}$ & ND & ND & ND \\
\hline Chloroform fraction of $\mathrm{Zm}$ & $7.2 \pm 0.02$ & $0.01 \pm 0.001$ & $42.7 \pm 0.69$ \\
\hline Ethyl acetate fraction of $Z m$ & $1.4 \pm 0.03$ & $0.05 \pm 0.001$ & $55.5 \pm 1.52$ \\
\hline Butanol fraction of $\mathrm{Zm}$ & $0.66 \pm 0.01$ & $0.05 \pm 0.001$ & $47.23 \pm 1.2$ \\
\hline Ethanol extract of $O p$ & $2.42 \pm 0.01$ & $0.09 \pm 0.001$ & $55.6 \pm 0.25$ \\
\hline Petroleum ether fraction of $O p$ & $4.85 \pm 0.02$ & $0.12 \pm 0.005$ & $53.3 \pm 2.5$ \\
\hline Chloroform fraction of $O p$ & $5.7 \pm 0.0$ & $0.12 \pm 0.0005$ & $58.5 \pm 1.4$ \\
\hline Ethyl acetate fraction of $O p$ & $2.4 \pm 0.03$ & $0.07 \pm 0.001$ & $99.4 \pm 0.94$ \\
\hline Butanol fraction of $O p$ & $2.23 \pm 0.3$ & $0.08 \pm 0.005$ & $65.3 \pm 0.7$ \\
\hline Ethanol extract of $S m$ & $1.96 \pm 0.01$ & $0.07 \pm 0.004$ & $79.4 \pm 1.3$ \\
\hline Petroleum ether fraction of $\mathrm{Sm}$ & $4.6 \pm 0.004$ & $0.092 \pm 0.01$ & $42.08 \pm 0.84$ \\
\hline Chloroform fraction of $\mathrm{Sm}$ & $3.6 \pm 0.005$ & $0.09 \pm 0.03$ & $24.2 \pm 1.2$ \\
\hline Ethyl acetate fraction of $S m$ & $0.43 \pm 0.03$ & $0.01 \pm 0.03$ & $38.14 \pm 1.04$ \\
\hline Butanol fraction of $S m$ & $1.2 \pm 0.02$ & $0.04 \pm 0.02$ & $45.6 \pm 0.9$ \\
\hline
\end{tabular}

Zm: Zataria multiflora, Op: Otostegia Persica, Sm: Salvia mirzayanii, NA: nonactive.

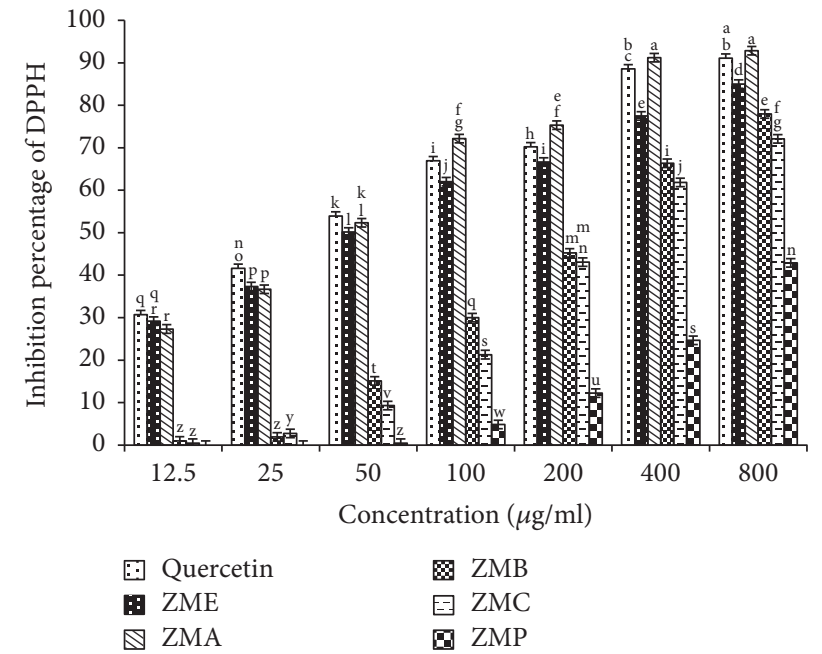

FIGURE 2: DPPH radical scavenging of Zataria multiflora extract and its fractions in comparison with quercetin as an antioxidant standard.

$S m$, and $Z m$ and their fractions. It is shown that potency of $\alpha$-amylase inhibition is related to the presence of certain compounds such as tannins, phenols, flavonoids, and compounds with antioxidant activities [18, 19]. So we investigated the presence of the phenolic compounds and flavonoids and the antioxidant powers of the samples with two methods including DPPH radical scavenging and reducing power. The antioxidant potentials of $\mathrm{Sm}$ extract and its fractions were reported in other study [20].

In our study, OPA showed the highest inhibition of $\alpha$ amylase $(99.4 \pm 0.94 \%$, Table 3$)$ activity which could be attributed to the presence of polyphenols $(7.072 \pm 0.11 \mathrm{mg} \mathrm{GAE} / \mathrm{g}$

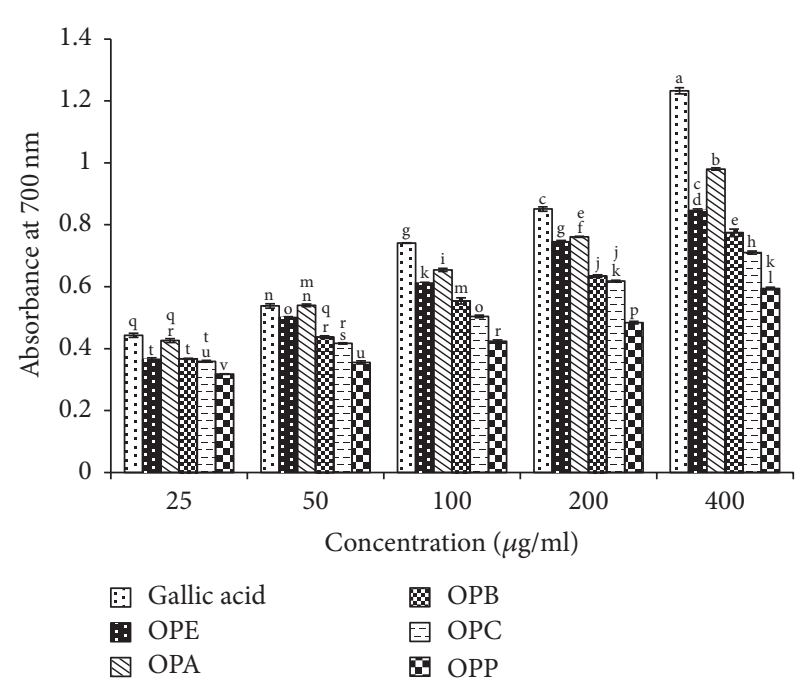

FIGURE 3: Reducing power of Otostegia persica extract and its fractions in comparison with gallic acid as an antioxidant standard.

sample, Table 1) and flavonoids (40.37 $\pm 1.06 \mathrm{mg}$ QUE/g sample, Table 1). Not only are polyphenols capable of reducing oxidative stress but also they inhibit carbohydrate hydrolyzing enzymes because of their abilities for binding proteins [21, 22]. Our results are in accordance with a previous study, in which there was a positive correlation between total polyphenols and flavonoids contents and the ability to inhibit intestinal $\alpha$-glucosidases and pancreatic $\alpha$-amylase [21-24]. In our study, acarbose was used as the positive control; it inhibits the $\alpha$-amylase activity at a concentration of $7.4 \mathrm{mg} / \mathrm{ml}, 100 \%$, and using the same concentration of $O P A$, an inhibition of about $99 \%$ was obtained. This indicates that $O P A$ is very potent in 


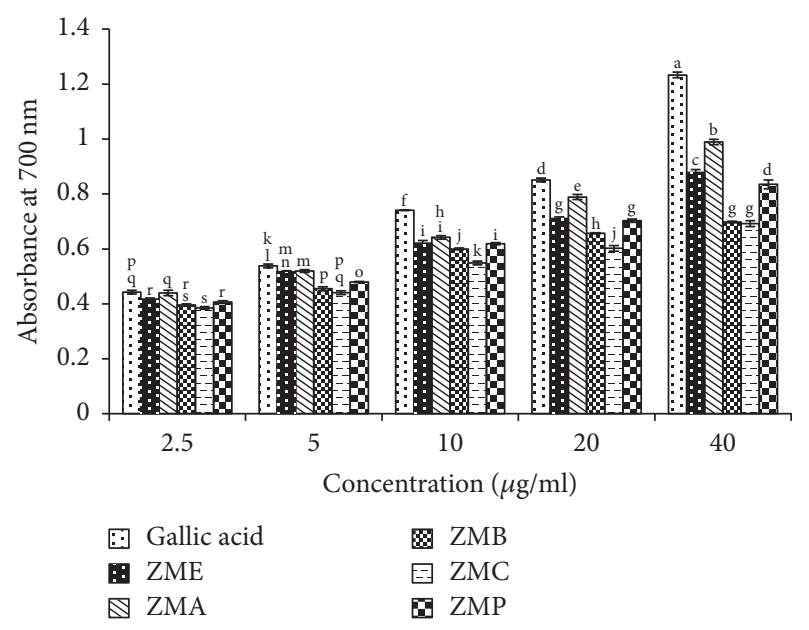

FIGURE 4: Reducing power of Zataria multiflora extract and its fractions in comparison with gallic acid as an antioxidant standard.

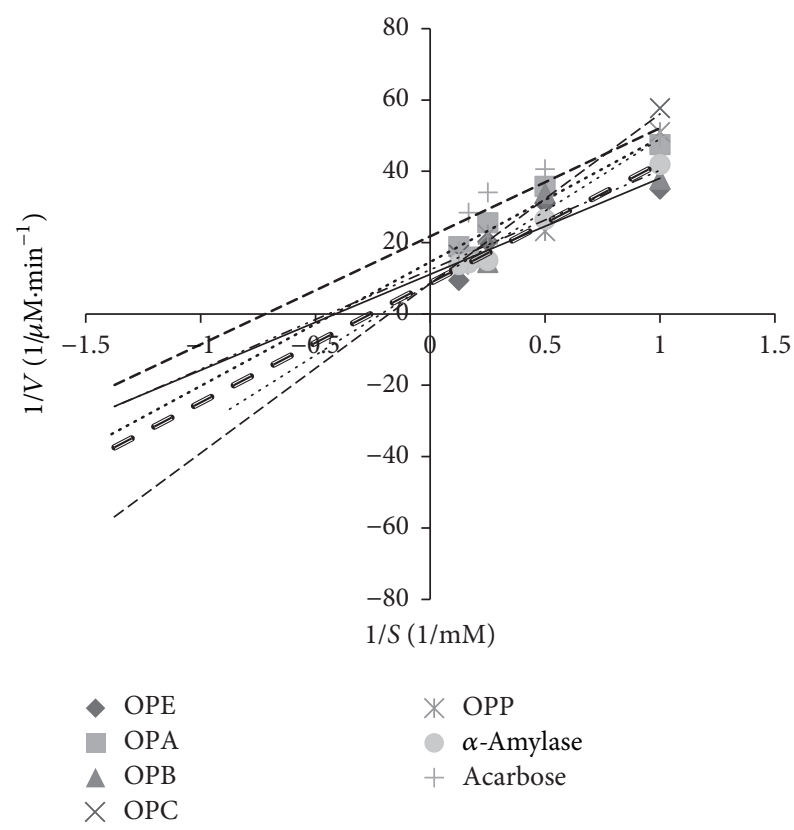

FIgURE 5: Kinetic analysis of $\alpha$-amylase inhibition by Otostegia persica extract and its fractions.

$\alpha$-amylase inhibition. This could justify the nature of some extract constituents (phenols, flavonoids saponins, steroids, alkaloids, and terpenoids) which are present in the extract and effective inhibitors of $\alpha$-amylase [25, 26]. Oxidative stress plays a pivotal role in the development of diabetic complications. Free radicals are formed disproportionately during diabetes due to glucose oxidation and the subsequent oxidative degradation of glycated proteins [2]. In addition, the diabetic patients have enhanced cellular oxidative stress and reduced antioxidant potentials which lead to defective antioxidant status [27]. In the present study, also the antioxidant

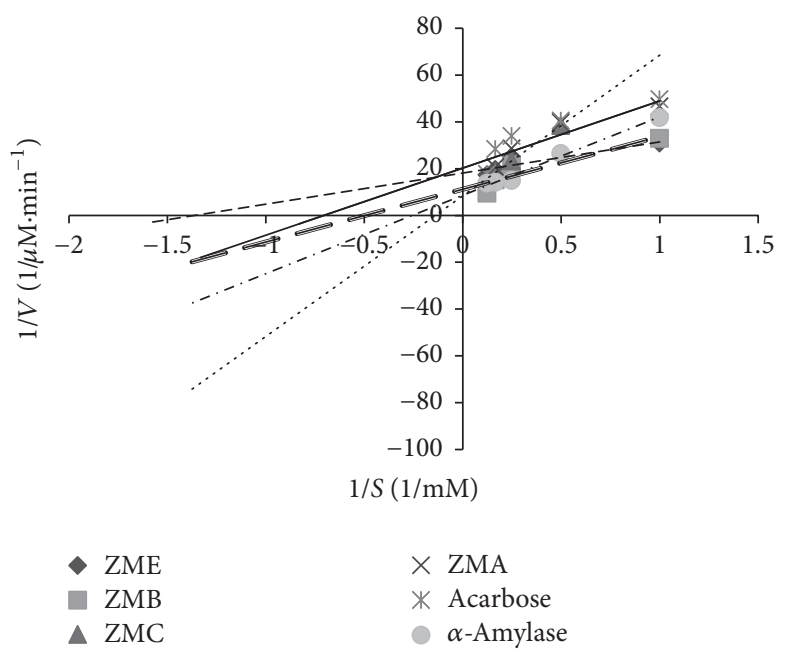

FIGURE 6: Kinetic analysis of $\alpha$-amylase inhibition by Zataria multiflora extract and its fractions.

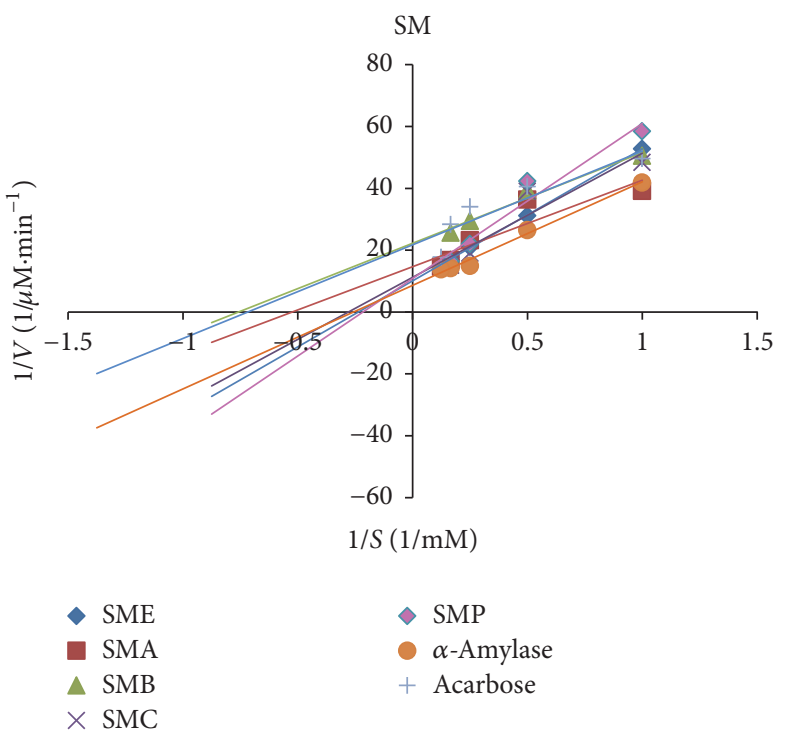

FIGURE 7: Kinetic analysis of $\alpha$-amylase inhibition by Salvia mirzayanii extract and its fractions.

capacities (by DPPH radical scavenging in Figures 1 and 2 and reducing power in Figures 3 and 2) and the presence of flavonoids and polyphenolics have been evaluated that could contribute to hypoglycemic activities. The effect of antioxidants on DPPH radical scavenging was thought to be due to their hydrogen-donating ability [9]. The correlation between antioxidant activity and the content of phenolic compounds has also been reported by many researchers. We find that the highest phenolic compounds and flavonoids exist in ZMA (17.21 $\pm 0.17 \mathrm{mg}$ GAE/g sample, $218.19 \pm$ $2.76 \mathrm{mg}$ QUE/g sample, resp.) and it has the highest reducing power and radical scavenging with $55.5 \pm 1.52 \% \alpha$-amylase inhibitory power. The least amounts of phenolic compounds and flavonoids were found in ZMP $(2.14 \pm 0.03 \mathrm{mg} \mathrm{GAE} / \mathrm{g}$ 
sample and $5.83 \pm 0.20 \mathrm{mg}$ QUE/g sample, resp.). Also, the lowest reducing power with no antidiabetic $\alpha$-amylase inhibition is observed in this fraction of $\mathrm{Zm}$. Among extract and different fractions of $O P, O P A$ had the highest phenolic compounds (7.07 $\pm 0.11 \mathrm{mg}$ GAE/g sample) and flavonoids (40.37 $\pm 1.06 \mathrm{mg}$ QUE/g sample) and the highest reducing power with $(99.4 \pm 0.94 \%) \alpha$-amylase inhibitory power (Table 3). The lowest phenolic compounds and flavonoids were in found in OPC $(0.90 \pm 0.032 \mathrm{mg} \mathrm{GAE} / \mathrm{g}$ sample and $24.25 \pm 1.24 \mathrm{mg}$ QUE/g sample, resp.). Ethanol extract of $O P$ had the highest flavonoids (57.07 $\pm 1.03 \mathrm{mg}$ QUE/g sample) and other workers have also found that phenolic compounds such as flavonoids which have the ability to scavenge free radicals are in the polar fractions of plant extracts [28]. Generally, $Z m$ fractions possess notably high phenolic and flavonoid compounds in comparison with $O P$ fractions $(p \leq$ $0.05)$. Abdali et al. described that the presence of thymol and carvacrol in $Z m$ is responsible for its antioxidant activity [29]. There are many reports on the antioxidant and antidiabetic effects of $Z m$ and $O p$ which agree with our results $[16,26,30$ 33]. Lineweaver-Burk plot is frequently used for identification of the likely mechanism of enzyme inhibition [34]. Plots were prepared by the reciprocal of product formation rate $(1 / V 0)$ versus the reciprocal of substrate concentrations. The initial velocities $(V 0)$ were determined from the slope of the linear parts of the curves of product amounts, in terms of $\mathrm{mM}$ of maltose equivalents, versus time in minutes (data not shown). Here, Lineweaver-Burk plot was depicted for both samples and acarbose as the standard inhibitor of porcine pancreatic $\alpha$-amylase (PPA). Acarbose is a strong competitive inhibitor of $\alpha$-amylase. This compound has a pseudosugar ring and the glycosidic nitrogen linkage that mimics the transition state for the enzymatic cleavage of glycosidic bond and hence competitively inhibits $\alpha$-amylase [34]. In our study, Lineweaver-Burk plots of the extracts showed different patterns. For the first time (Figures 5-7), the mechanisms of $\alpha$-amylase inhibition of $\mathrm{Zm}, \mathrm{Sm}$, and $\mathrm{Op}$ extracts and their different fractions were investigated and the results showed that some of the fractions inhibited $\alpha$-amylase through uncompetitive mechanism (like ZMA, ZME, ZMB, OPE, $O P A$, and $O P B$ ) and $Z M C, O P P, O P C$, and $S M P$ inhibited $\alpha$ amylase through competitive mechanism. Probably, there are some compounds in the samples that could compete with the substrate for binding to the active site of the enzyme and some of them do not compete with the substrate but bind to the other sites of the enzyme. In this study, most of the samples are uncompetitive inhibitors and one advantage of these inhibitors is that they would be effective at lower concentrations of substrate in comparison with competitive inhibitors which require higher concentrations of the substrate for the same effects.

\section{Conclusion}

The findings of this study clarify that phenolic compounds present in leaves extracts of $Z m$ and $O p$ species may be responsible for their observed activities. Thus a few traditional Iranian medicinal plants, particularly $Z m, S m$, and $O p$, seem to act as potential $\alpha$-amylase inhibitors in the management of diabetes.

\section{Disclosure}

This manuscript was extracted from M.S. thesis of Elham Pimoradloo presented as partial fulfillment of the requirements for obtaining M.S. degree in biochemistry at Shiraz Azad University.

\section{Conflicts of Interest}

The authors declare that there are no conflicts of interest regarding with this study.

\section{Acknowledgments}

The authors acknowledge Hormozgan University of Medical Sciences for providing Grant no. 9316 and Shiraz University of Medical Sciences Grant no. 92-01-70-7075 for performing this project.

\section{References}

[1] Y. Lin and Z. Sun, "Current views on type 2 diabetes," Journal of Endocrinology, vol. 204, no. 1, pp. 1-11, 2010.

[2] A. C. Maritim, R. A. Sanders, and J. B. Watkins III, "Diabetes, oxidative stress, and antioxidants: a review," Journal of Biochemical and Molecular Toxicology, vol. 17, no. 1, pp. 24-38, 2003.

[3] L. Liu, M. A. Deseo, C. Morris, K. M. Winter, and D. N. Leach, "Investigation of $\alpha$-glucosidase inhibitory activity of wheat bran and germ," Food Chemistry, vol. 126, no. 2, pp. 553-561, 2011.

[4] F. Masjedi, A. Gol, and S. Dabiri, "Preventive effect of garlic (Allium sativum L.) on serum biochemical factors and histopathology of pancreas and liver in streptozotocin-induced diabetic rats," Iranian Journal of Pharmaceutical Research, vol. 12, no. 3, pp. 325-338, 2013.

[5] F. Naghibi, M. Mosaddegh, and M. Mohammadi Motamed, "Labiatae family in folk medicine in Iran: from ethnobotany to pharmacology," Iranian Journal of Pharmaceutical Research, vol. 4, no. 2, pp. 63-79, 2005.

[6] J. B. Walker, K. J. Sytsma, J. Treutlein, and M. Wink, "Salvia (Lamiaceae) is not monophyletic: Implications for the systematics, radiation, and ecological specializations of Salvia and tribe Mentheae," American Journal of Botany, vol. 91, no. 7, pp. 1115$1125,2004$.

[7] S. Moeina and M. Moeinb, "Antioxidant activities and phenolic content of Juniperus excelsa extract," Iranian Journal of Pharmaceutical Sciences, vol. 6, no. 2, pp. 133-140, 2010.

[8] P. M. de Sales, P. M. de Souza, L. A. Simeoni, P. D. O. Magalhães, and D. Silveira, " $\alpha$-amylase inhibitors: a review of raw material and isolated compounds from plant source," Journal of Pharmacy and Pharmaceutical Sciences, vol. 15, no. 1, pp. 141$183,2012$.

[9] Y. Zou, Y. Lu, and D. Wei, "Antioxidant activity of a flavonoidrich extract of Hypericum perforatum L. in vitro," Journal of Agricultural and Food Chemistry, vol. 52, no. 16, pp. 5032-5039, 2004.

[10] T. S. Kumar, S. Shanmugam, T. Palvannan, and V. M. B. Kumar, "Evaluation of antioxidant properties of Elaeocarpus ganitrus 
roxb. leaves," Iranian Journal of Pharmaceutical Research, vol. 7, no. 3, pp. 211-215, 2008.

[11] X.-J. Duan, W.-W. Zhang, X.-M. Li, and B.-G. Wang, "Evaluation of antioxidant property of extract and fractions obtained from a red alga, Polysiphonia urceolata," Food Chemistry, vol. 95, no. 1, pp. 37-43, 2006.

[12] S. Moein, B. Farzami, S. Khaghani, M. R. Moein, and B. Larijani, "Antioxidant properties and prevention of cell cytotoxicity of Phlomis persica Boiss.," Daru, vol. 15, no. 2, pp. 83-88, 2007.

[13] A. O. Ademiluyi, G. Oboh, A. A. Boligon, and M. L. Athayde, "Effect of fermented soybean condiment supplemented diet on $\alpha$-amylase and $\alpha$-glucosidase activities in Streptozotocininduced diabetic rats," Journal of Functional Foods, vol. 9, no. 1, pp. 1-9, 2014.

[14] Y.-M. Kim, Y.-K. Jeong, M.-H. Wang, W.-Y. Lee, and H.-I. Rhee, "Inhibitory effect of pine extract on $\alpha$-glucosidase activity and postprandial hyperglycemia," Nutrition, vol. 21, no. 6, pp. 756761, 2005.

[15] F. Moradi-Afrapoli, B. Asghari, S. Saeidnia et al., "In vitro $\alpha$ glucosidase inhibitory activity of phenolic constituents from aerial parts of Polygonum hyrcanicum," DARU, Journal of Pharmaceutical Sciences, vol. 20, no. 1, article no. 37, 2012.

[16] C. N. Kunyanga, J. K. Imungi, M. W. Okoth, H. K. Biesalski, and V. Vadivel, "Total phenolic content, antioxidant and antidiabetic properties of methanolic extract of raw and traditionally processed Kenyan indigenous food ingredients," LWT Food Science and Technology, vol. 45, no. 2, pp. 269-276, 2012.

[17] B. Dineshkumar, A. Mitra, and M. Manjunatha, "A comparative study of alpha amylase inhibitory activities of common antidiabetic plants at Kharagpur 1 block," International Journal of Green Pharmacy, vol. 4, no. 2, pp. 115-121, 2010.

[18] S. Jo, E. Ka, and H. Lee, "Comparison of antioxidant potential and rat intestinal a-glucosidases inhibitory activities of quercetin, rutin, and isoquercetin," vol. 2, pp. 52-60, 2009.

[19] S. Asadi, F. Khodagholi, M. A. Esmaeili et al., "Chemical composition analysis, antioxidant, antiglycating activities and neuroprotective effects of S. choloroleuca, S. mirzayanii and S. santolinifolia from Iran," American Journal of Chinese Medicine, vol. 39, no. 3, pp. 615-638, 2011.

[20] S. Moein, B. Farzami, S. Khaghani, M. R. Moein, and B. A. Larijani, "Antioxidant properties and protective effect on cell cytotoxicity of Salvia mirzayani," Pharmaceutical Biology, vol. 45, no. 6, pp. 458-463, 2007.

[21] K. M. Ramkumar, B. Thayumanavan, T. Palvannan, and P. Rajaguru, "Inhibitory effect of Gymnema montanum leaves on $\alpha$-glucosidase activity and $\alpha$-amylase activity and their relationship withpolyphenolic content," Medicinal Chemistry Research, vol. 19, no. 8, pp. 948-961, 2010.

[22] E. Padilla-Camberos, E. Lazcano-Díaz, J. M. Flores-Fernandez, M. S. Owolabi, K. Allen, and S. Villanueva-Rodríguez, "Evaluation of the inhibition of carbohydrate hydrolyzing enzymes, the antioxidant activity, and the polyphenolic content of citrus limetta peel extract," The Scientific World Journal, vol. 2014, Article ID 121760, 4 pages, 2014.

[23] F. T. Bothon, E. Debiton, F. Avlessi, C. Forestier, J.-C. Teulade, and D. K. Sohounhloue, "In vitro biological effects of two antidiabetic medicinal plants used in Benin as folk medicine," BMC Complementary and Alternative Medicine, vol. 13, article 51, 2013.

[24] T. T. Mai, N. N. Thu, P. G. Tien, and N. van Chuyen, "Alphaglucosidase inhibitory and antioxidant activities of Vietnamese edible plants and their relationships with polyphenol contents," Journal of Nutritional Science and Vitaminology, vol. 53, no. 3, pp. 267-276, 2007.

[25] Z. Sadeghi, M. Akaberi, and J. Valizadeh, "Otostegia persica (Lamiaceae): A review on its ethnopharmacology, phytochemistry, and pharmacology," Avicenna journal of phytomedicine, vol. 4, no. 2, pp. 79-88, 2014.

[26] N. Yassa, F. Sharififar, and A. Shafiee, "Otostegia persica as a source of natural antioxidants," Pharmaceutical Biology, vol. 43, no. 1, pp. 33-38, 2005.

[27] J. S. Johansen, A. K. Harris, D. J. Rychly, and A. Ergul, “Oxidative stress and the use of antioxidants in diabetes: linking basic science to clinical pratice," Cardiovascular Diabetology, vol. 4, article 5, 2005.

[28] E. Valizadeh, N. F. Zonouz, A. Zand, S. Shahbazi, and A. Malekian, "Evaluation of antioxidant potentials of extracts of cotton thistle (Onopordum leptolepis DC.) obtained by various solvents," Australian Journal of Crop Science, vol. 5, no. 10, pp. 1163-1166, 2011.

[29] K. Abdali, L. Jahed, S. Amooee, M. Zarshenas, H. Tabatabaee, and R. Bekhradi, "Comparison of the Effect of Vaginal Zataria multiflora Cream and Oral Metronidazole Pill on Results of Treatments for Vaginal Infections including Trichomoniasis and Bacterial Vaginosis in Women of Reproductive Age," BioMed Research International, vol. 2015, Article ID 683640, 2015.

[30] F. Sharififar, M. H. Moshafi, S. H. Mansouri, M. Khodashenas, and M. Khoshnoodi, "In vitro evaluation of antibacterial and antioxidant activities of the essential oil and methanol extract of endemic Zataria multiflora Boiss," Food Control, vol. 18, no. 7, pp. 800-805, 2007.

[31] R. Sharafati Chaleshtori, M. Rafieian Kopaei, N. Rokni, S. Mortezaei, and A. Sharafati Chaleshtori, "Antioxidant activity of Zataria multiflora hydroalcoholic extract and its antibacterial effect on Staphylococcus aureus," Journal of Mazandaran University of Medical Sciences, vol. 22, no. 1, pp. 87-94, 2013.

[32] G. Sepehri, M. Khaksari, A. G. Najar et al., "The effect of water extract of Zataria multiflora on microvascular permeability in streptozocin induced diabetic rats," Annual Research and Review in Biology, vol. 4, no. 20, 3119 pages, 2014.

[33] Z. Tofighi, F. Alipour, H. Hadavinia, M. Abdollahi, A. Hadjiakhoondi, and N. Yassa, "Effective antidiabetic and antioxidant fractions of Otostegia persica extract and their constituents," Pharmaceutical Biology, vol. 52, no. 8, pp. 961-966, 2014.

[34] M. Rahimzadeh, S. Jahanshahi, S. Moein, and M. R. Moein, "Evaluation of alpha- amylase inhibition by Urtica dioica and Juglans regia extracts," Iranian Journal of Basic Medical Sciences, vol. 17, no. 6, pp. 466-470, 2014. 

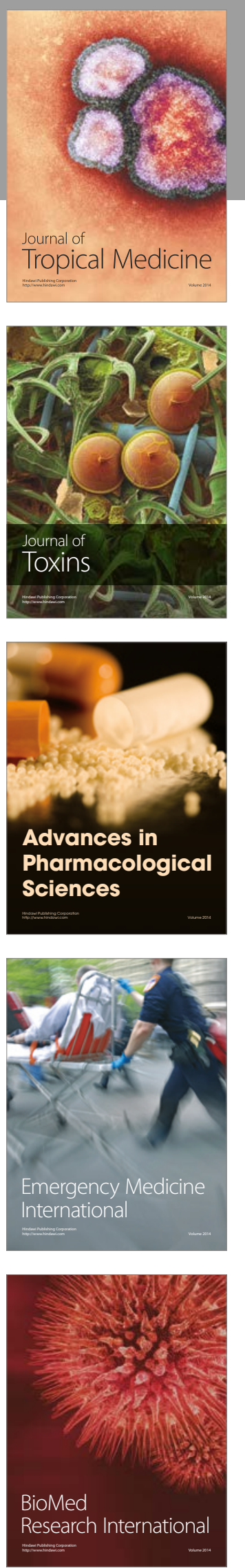
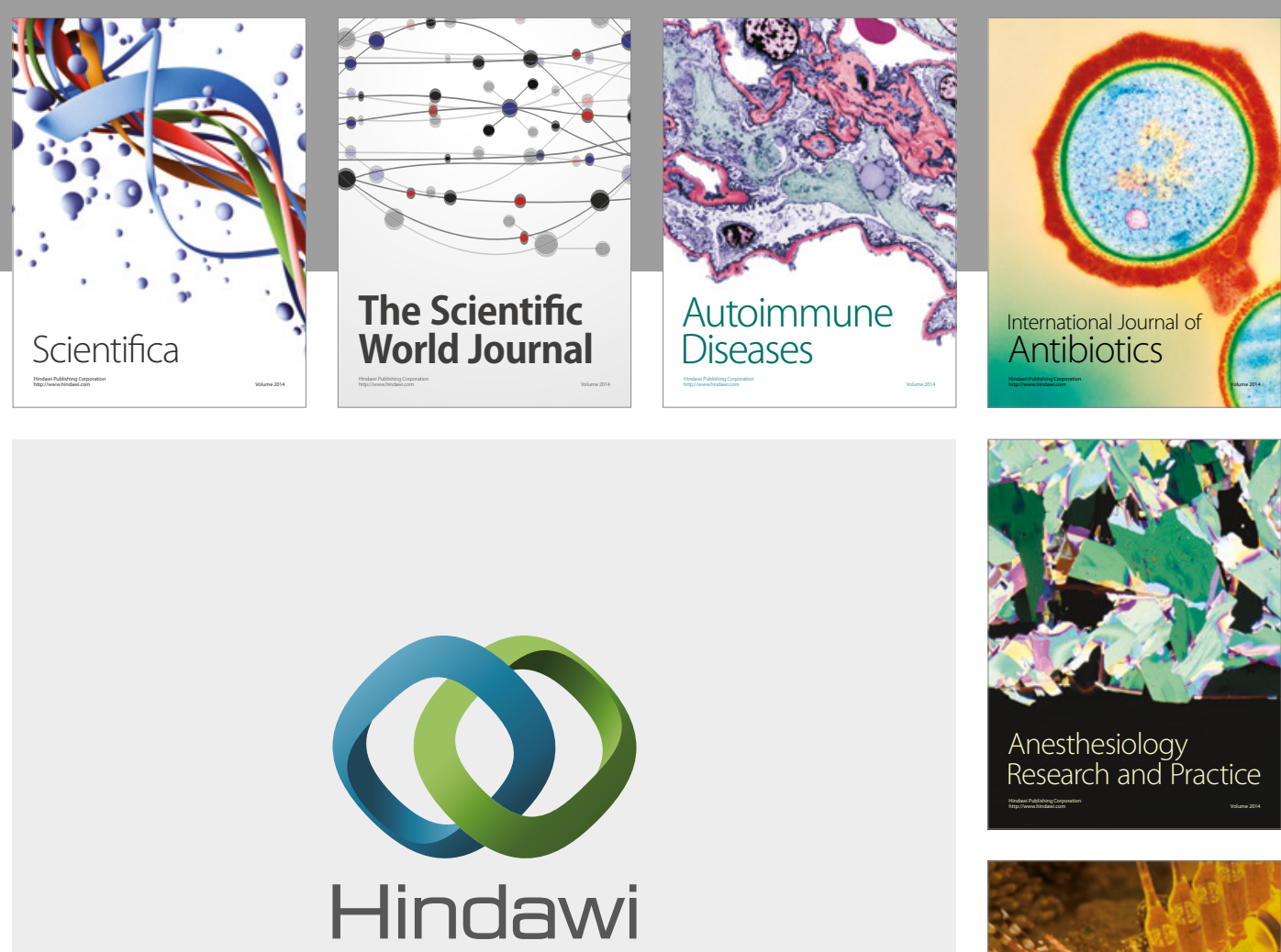

Submit your manuscripts at

https://www.hindawi.com
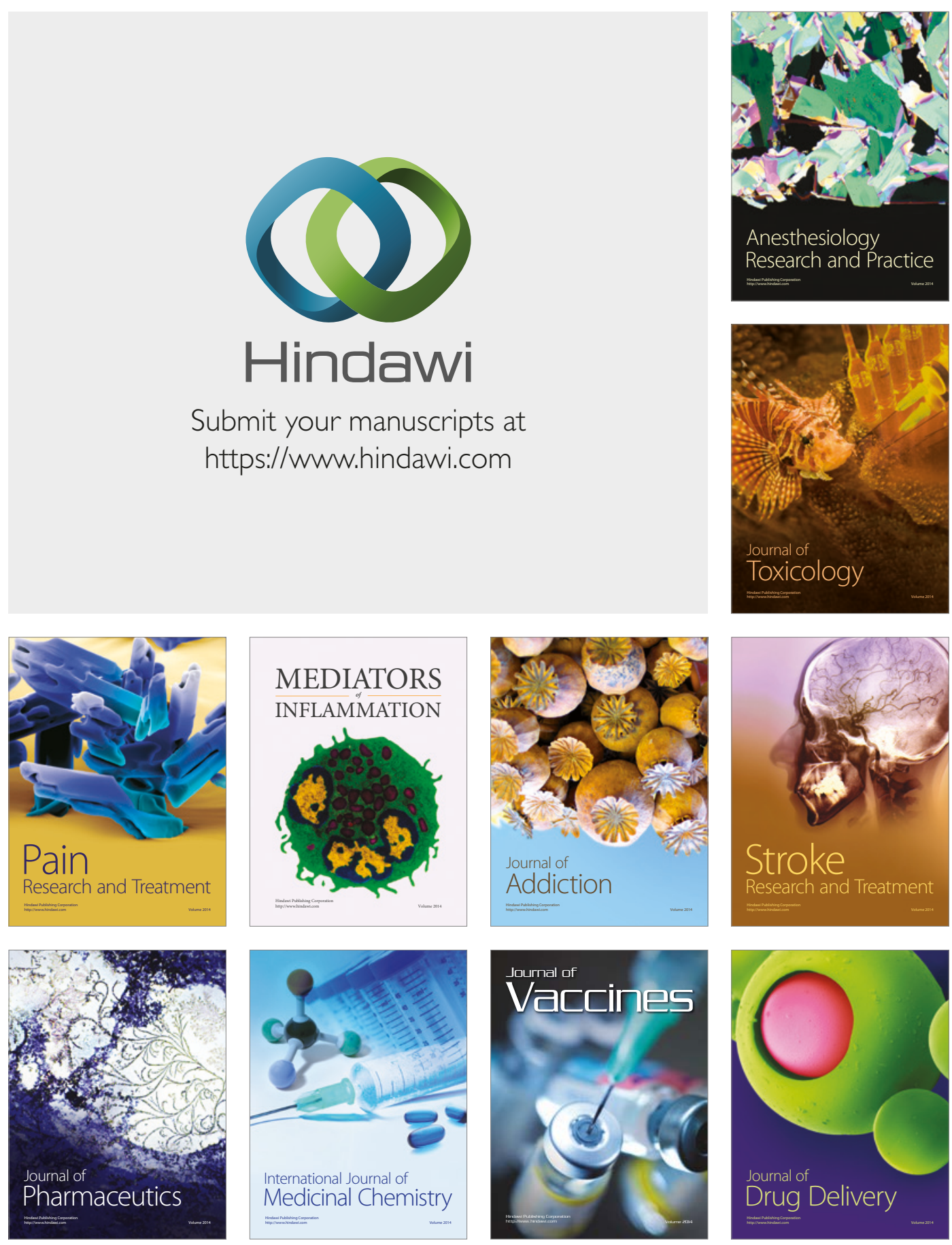